\title{
Heuristic Dispatch Based on Price Signals for Behind-the-Meter PV- Battery Systems in the System Advisor Model
}

Brian Mirletz and Darice Guittet June 23, 2021 


\section{System Advisor Model (SAM)}

Free software that enable detailed performance and financial analysis for renewable energy systems
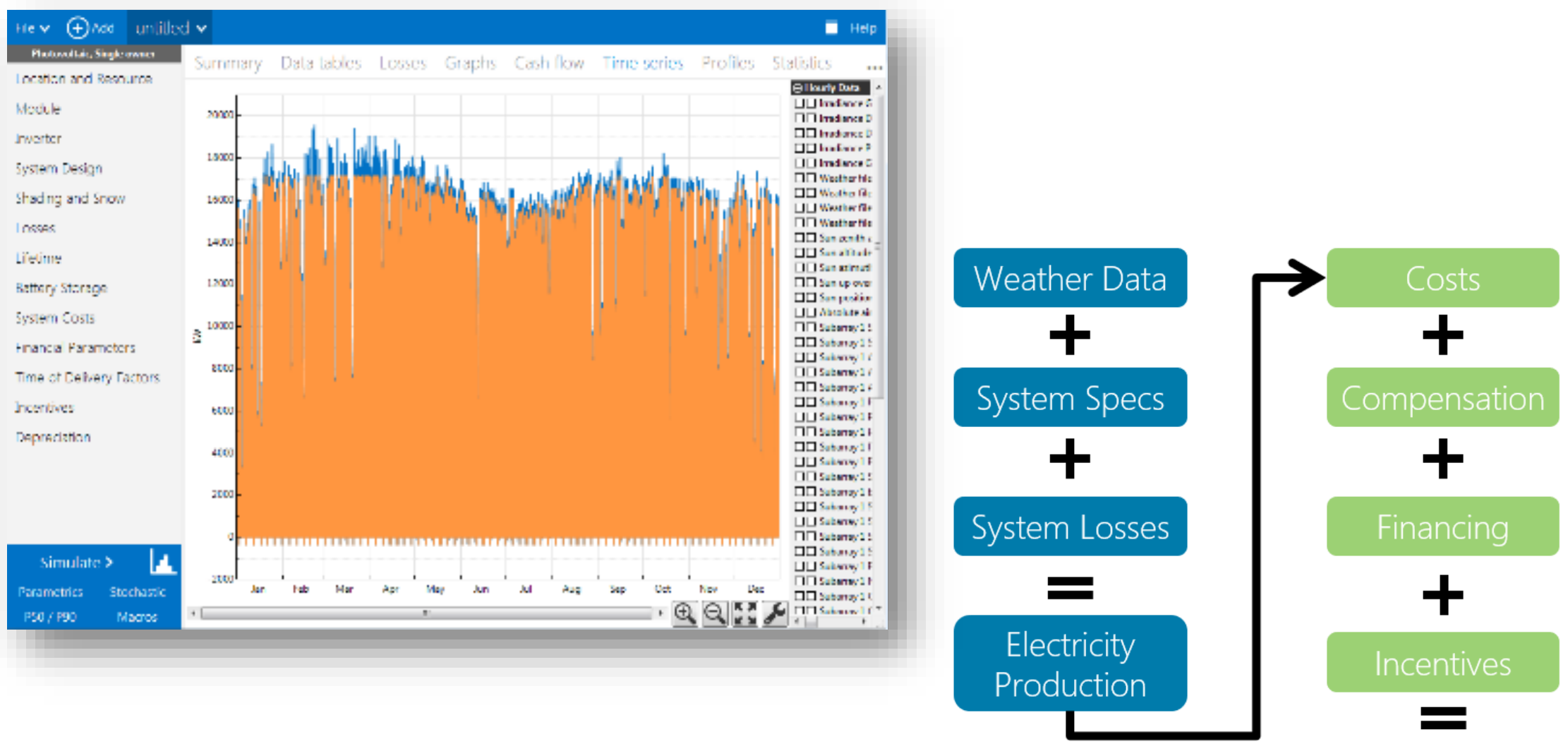

Results

Annual, Monthly, and Hourly Output, Capacity Factor, LCOE, NPV, Payback, Revenue

http://sam.nrel.gov/download https://github.com/NREL/SAM 


\section{Behind The Meter Dispatch Modes}

Dispatch Mode

Inputs
Use Case

\begin{tabular}{|c|c|c|}
\hline Peak Shaving (look ahead) & $\begin{array}{c}\text { Upcoming PV and Load } \\
\text { forecast }\end{array}$ & Peak Demand Charges \\
\hline Peak Shaving (look behind) & $\begin{array}{c}\text { Yesterday's actual PV and } \\
\text { Load }\end{array}$ & $\begin{array}{c}\text { Peak Demand Charges (worst } \\
\text { case) }\end{array}$ \\
\hline Input Grid Power Targets & $\begin{array}{l}\text { Monthly or time series } \\
\text { targets }\end{array}$ & $\begin{array}{c}\text { Specify more detailed peak } \\
\text { power }\end{array}$ \\
\hline Custom Dispatch & Time series & $\begin{array}{l}\text { PySAM / outside } \\
\text { optimization }\end{array}$ \\
\hline Manual Dispatch & Schedule by hour and month & Energy Arbitrage \\
\hline Price Signals Dispatch & $\begin{array}{l}\text { Upcoming PV and Load } \\
\text { forecast, utility rates }\end{array}$ & $\begin{array}{c}\text { Mix of TOU charges and } \\
\text { demand charges, battery } \\
\text { degradation }\end{array}$ \\
\hline
\end{tabular}

Bold: defaults

Italics: Available in PVWatts-Battery model 
1. Forecast cost of utility bill without dispatch

2. Schedule discharge to the load for the highest cost periods according to: $P_{\text {discharge }, t}=\frac{E_{\text {remaining }, t} * C_{t}}{\left(\sum_{i=t}^{p} C_{i}\right) * d t}$

3. Schedule charging for the lowest marginal cost periods 4. Reduce discharging or charging based on expected SOC 5. Repeat 2-4 to generate plans with 0 to 12 hours of dispatch 6. Select lowest cost plan according to:

$$
C_{\text {total }}=C_{\text {utility_bill }}+C_{\text {cycle }} * n_{\text {cycles }}-E_{\text {remaining }} * C_{\text {marginal }}
$$




\section{Sensitivity Analysis}

\begin{tabular}{|c|c|c|}
\hline Parameter & Min Value & Max Value \\
\hline Max Energy Charge & $\$ 0.10 / \mathrm{kWh}$ & $\$ 0.50 / \mathrm{kWh}$ \\
\hline Ratio of TOU Periods & 1 & 10 \\
\hline Fixed Demand Charge & $\$ 0 / \mathrm{kW}$ & $\$ 59.05 / \mathrm{kW}$ \\
\hline TOU Demand Charge & $\$ 0 / \mathrm{kW}$ & $\$ 13.45 / \mathrm{kW}$ \\
\hline
\end{tabular}




\section{Sensitivity Results by Demand Charge Percentage}

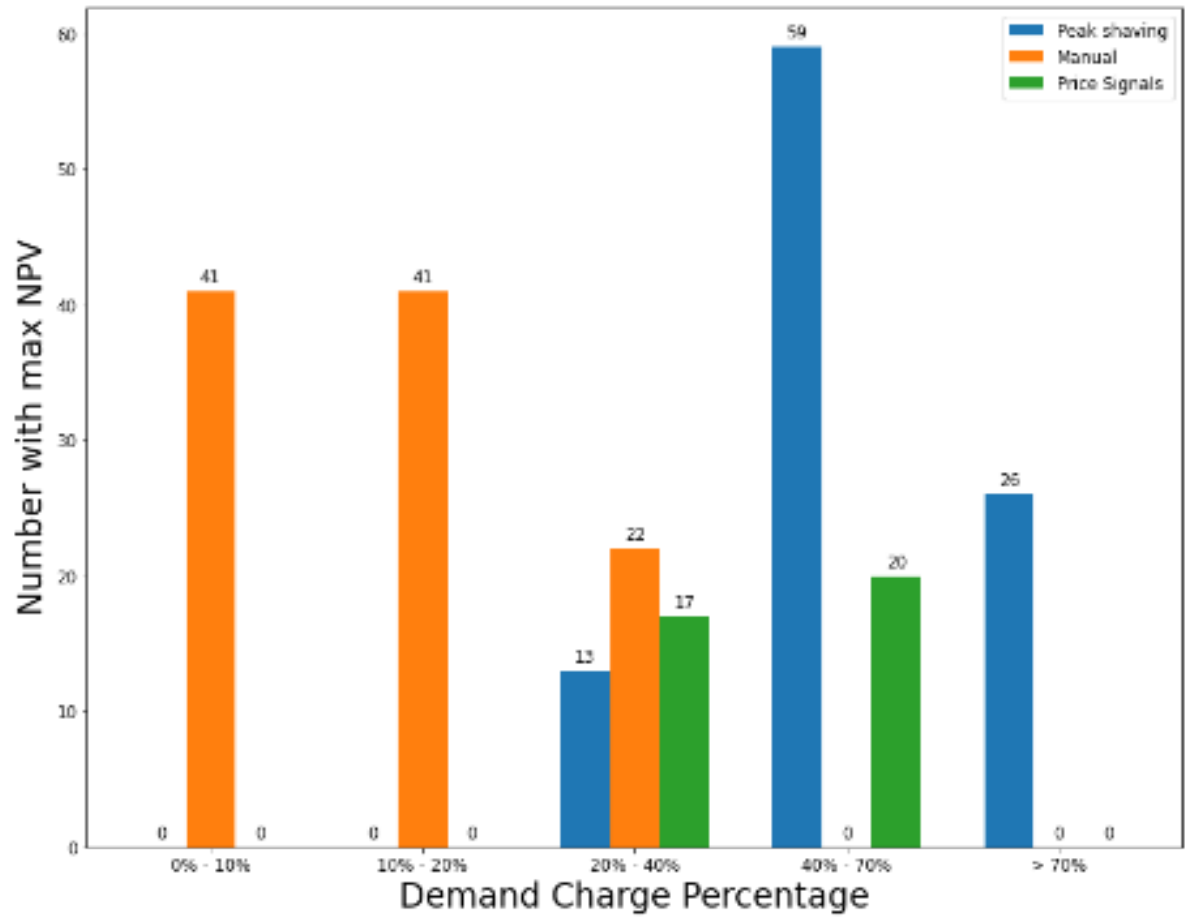

Sensitivity Results by Replacement Srategy

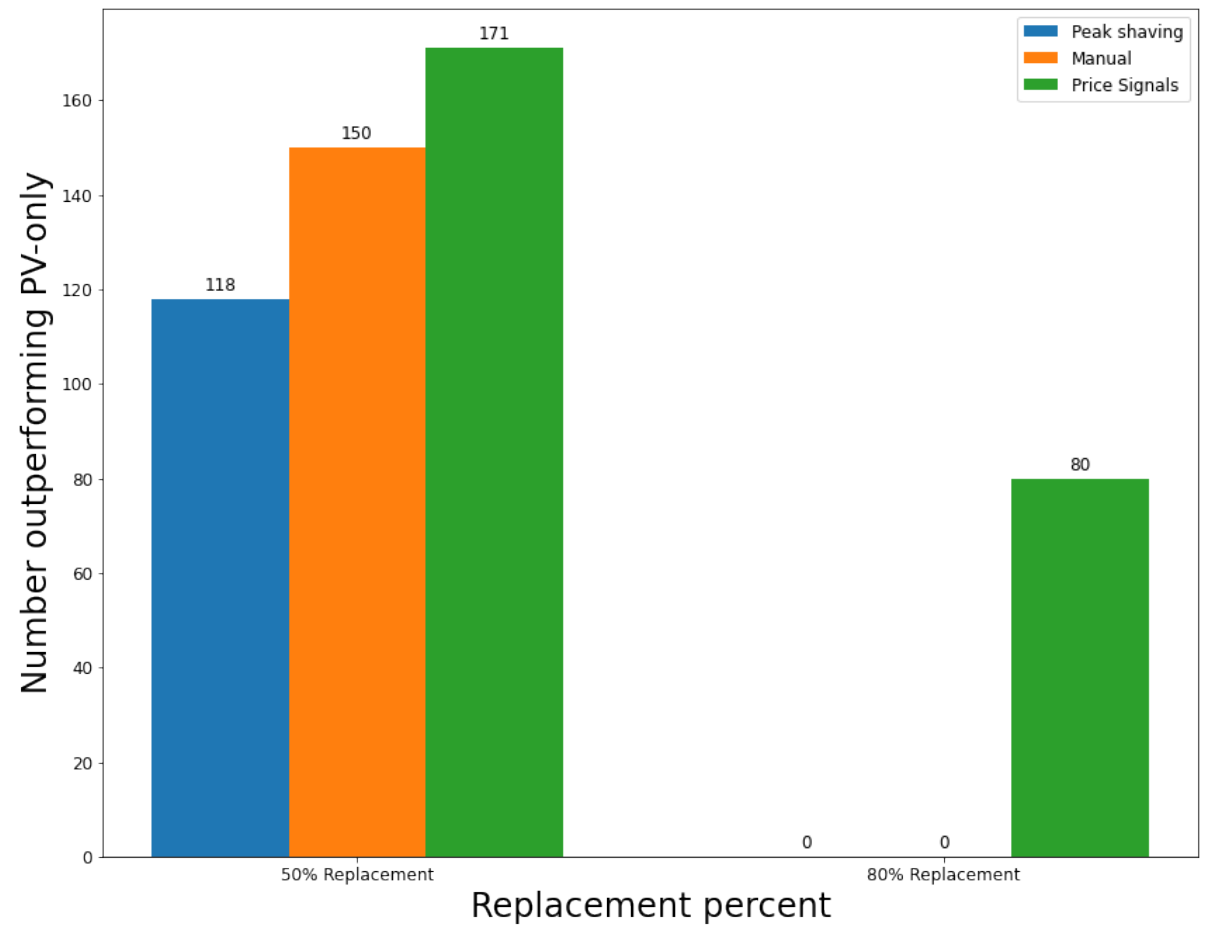




\section{Thank you!}

This work was authored by the National Renewable Energy Laboratory, operated by Alliance for Sustainable Energy, LLC, for the U.S. Department of Energy (DOE) under Contract No. DE-AC36-08GO28308. Funding provided by the U.S. Department of Energy Office of Energy Efficiency and Renewable Energy Solar Energy Technologies Office. The views expressed in the article do not necessarily represent the views of the DOE or the U.S. Government. The U.S. Government retains and the publisher, by accepting the article for publication, acknowledges that the U.S. Government retains a nonexclusive, paid-up, irrevocable, worldwide license to publish or reproduce the published form of this work, or allow others to do so, for U.S. Government purposes.

\author{
www.nrel.gov \\ http://sam.nrel.gov \\ GNREL \\ NATIONAL RENEWABLE ENERGY LABORATORY
}

